\title{
The personality of a teacher in contemporary socio-cultural space
}

\author{
Isita Muskhanova*, Fatima Bazayeva, and Khouzou Mamalova \\ Chechen State Pedagogical University, Grozny, Russia
}

\begin{abstract}
The article deals with issues related to the formation of the personality of a future teacher. The main goal of modern education system is to form an intellectual, moral and harmonious personality. Therefore, the teacher is entrusted with the mission to be a translator and navigator in the information space. development of a future teacher's personality in the modern socio-cultural space is conditioned by motivational settings to achieve positive results of own activity, conditions of self-realization in the process of university training, participation of teacher trainees in national projects and contests of teaching skills, providing modern infrastructure of higher school teachers' training system.
\end{abstract}

\section{Introduction}

The issues related to the formation of a future teacher's personality are of particular relevance. In our opinion, this is primarily due to transformational processes leading to rapid changes in our reality. The global objective of education is to form an intellectual, moral, harmonious personality capable of transforming the surrounding world in accordance with the challenges that determine the development trajectory of each person. Moreover, under the conditions of modernization of the educational paradigm, the teacher should act not only as a transmitter of knowledge and socio-cultural experience, but also as a navigator in the information space. This special mission determines new large-scale tasks for the person who chooses the path of a teacher. It is this special mission of a teacher that determines the necessity of comprehensive teacher training for future activities in the process of higher education. Thus, one cannot but agree with the opinion of a group of researchers who argue for the importance of research training of future teachers, contributing to the formation of personality, ready to successfully integrate into the modern socio-cultural space in the context of increasing interethnic and inter-linguistic contacts [1].

Modern socio-cultural space as a set of conditions that promote personal development can be characterized in two ways: on the one hand, it is an opportunity for self-actualization, self-disclosure, on the other hand, it is a situation of high anxiety and uncertainty. Due to the expansion of multilevel information, the cognitive sphere of a personality undergoes changes, the meaning and value orientations are devalued in the human consciousness, which can lead to irreversible processes. The fact that the personality of a modern person is influenced by different cultures, which actualizes personally meaningful motivation for a student, is of no

\footnotetext{
*Corresponding author: vinter_65@mail.ru
} 
small importance. In this connection, ensuring productive cooperation and interaction of all subjects of learning activities in the process of solving project-creative tasks, stimulates the process of personal enculturation [2]. The culturological approach contributes to the most effective formation of harmonious synthesis of universal and national-regional cultures. Therefore, one of the urgent tasks of modern pedagogy is to find educational models that meet the new stage of civilization development and correspond to the modern type of culture [3]. As stated in [4] Since the forefront of modernization restructuring is a human being as a social actor, a carrier of values and culture, the main indicator of progressiveness or reactivity of changes, the leading role in the evolutionary process belongs to the personal factor, and in the educational process - to the teacher's personality. Therefore, the most important strategic task becomes fundamental methodological and substantive training of an educator, whose creativity will be the basis for building the society of the future.

Ideas of meaning pedagogy and conceptual approach is one of the aspects of quality training of a school teacher. According to researchers [5] the creation of conceptual space that combines traditional approach and innovation should be the basis of professional education of future teacher. The preparation of future teachers should necessarily include purposeful formation of their system of internal, emotionally mastered values that will help them cope with complex socio-cultural problems in the upcoming professional activity [6]. In addition, many works emphasize the role of the teacher in the formation of intercultural competence [7].

The aim of the publication is to outline the study of modern socio-cultural space of education as a factor and environment for personal development of a future teacher.

\section{Research Methods}

The methodological basis of our study was structural-functional and comparative analysis, as well as the leading provisions of the problem, askiological and anthropological approaches. The issues of future teacher training, moral choice, and self-actualization are far from being exhaustive. A prerequisite for studying the important process of personal rebooting, social renewal, national and civic identity becomes an appeal to the metaphysical aspects of human personality. The methodology of science proceeds from the unity of the practice of knowledge and its value interpretation. This determines our theoretical and methodological position focused on the formation of a versatile personality of a future teacher, his world outlook, value picture of the world. The problematics of our research is set by the hierarchy of values, i.e. we attach special importance to the axiological dimension, since outside the value scale the processes of social transformation cannot be identified as development or non-development with the same degree of validity. The axiological basis of any innovation is a human being as a cognitive and creative person, a microcosm, a bearer of values, knowledge and competences. The axiological foundation of pedagogical education, its values and meanings, preservation and strengthening of national, cultural and professional identity of a teacher's personality provide national security and form the national narrative. The proposed understanding of innovation, which focuses on the individual as a possessor and transmitter of value, purpose, volitional and intellectual principles, allows to counteract the reduction of norms and values due to the overload of the space of life activity by information flows and many other factors. A significant part of the materials are tested at international and national conferences, forums, the results of the discourse on the modernization of teacher education, the search for mechanisms to improve the effectiveness of teacher training in the modern socio-cultural space.

\section{Finding}


Studying at a pedagogical university is a definite and significant period of student life, which affects the development of personal and professional qualities of a specialist, the development of his/her competences and competences for real pedagogical activity and success in the profession. Professional educationin a pedagogical university aims to develop not only intellectual, emotional-volitional sphere of a future teacher's personality, but also professional orientation, including professional honor, professional responsibility, professional dignity. In this process as a result of continuous moral choice based on the system of traditional cultural values that activate subjective position of a personality, the student's spiritual and practical activity is improved.

Consequently, while receiving higher education the future teacher receives not only training for professional pedagogical activity, but also the experience of creative selfrealization. Self-actualization in conditions of higher professional pedagogical education is a process of realization by a future teacher of his/her internal potential, which is connected with the goals of higher education. According to researchers, "self-realization is the process and result of dialectical fusion of a unique, inimitable personality and the objective world, which occurs as a result of a variety of learning activities" [8].

Self-realization prompts a future teacher to analyze deeply and consciously acquired professional knowledge, formed abilities and skills as a means of further professional and personal self-development. The phenomenon of reflection depending on the content of life tasks is of great importance for the development of an individual and a social community: reflection leads a person to a holistic view of his/her activity (content, ways and means), allows a person to take a critical view of himself/herself and his/her past, present and future activity, makes him/her a subject of his/her own activity in the profession. In the process of university training self-realization of a future teacher is connected with the formation of both professional and personal competences [9].

Self-understanding as one of the components of self- realizationof a future teacher contributes to the formation of his/her holistic idea of himself/herself, the content and ways, means of his/her activity, i.e. provides the search of meanings. Self-realization is also determined by the value component, which allows a future teacher to identify socially determined values of pedagogical activity and to form a value attitude towards the teaching profession. In educational practice, there are situations when a student, having studied several courses in a technical university, drops out of it. It is only after entering a pedagogical university that he or she becomes active, independent and interested in preparing for the classroom. The right choice of future profession contributes to self-affirmation and selfdevelopment, which makes it possible to discover self-esteem in the structure of selfactualisation, which allows a future teacher to recognise cognitive and professional qualities in himself and others and to relate them to educational and professional achievements. Selfesteem is seen as a judgement of a person's own worth, it reflects the level of development of a sense of self-esteem, a sense of self-worth, and also indicates a positive attitude towards everything that falls within the realm of one's self. A teacher with adequate self-esteem strives for innovation, creativity in his/her professional activity and contributes to the creative development of the student's personality. In the process of evaluation the meanings are formed into values, and self-esteem in unity with self-understanding gives a characteristic motivational function, since self-understanding determines the formation and formation of a pronounced and directed interest in the future teacher to know his inner world. Such an interest guarantees the formation of mature moral-value attitudes, awareness of one's needs. In addition, the meaningfulness of the disciplines studied is also important. In the context of socio-cultural space, in our opinion, moral-values attitudes are also formed by national literature, and their foundations are laid in the family $[10,11]$.

In the process of self-realisation, the student interacts with a significant "Other", actively assimilates norms and standards of interpersonal relations, and triggers the mechanism of 
self-development. Pedagogical communication and dialogical interaction between a student and a teacher ensure the learning process as a whole. The dialogue between the two subjects contributes to the removal of psychological barriers, emotional tension and support of the future teacher's interest in receiving pedagogical education.

Self-assertion is a person's need for self-esteem, an aspiration to assert oneself in the eyes of others and in one's own, to acquire certain properties of value for individual-personal development in general. Self-assertion is an awareness of oneself and an attitude towards oneself through the presentation of one's particular self to a significant "Other" as selfassertion [12,13]. Psychological and pedagogical science theoretically and empirically distinguishes three strategies of self-affirmation - self-suppression, constructive selfaffirmation and domination. Self-affirmation allows analyzing one's goals, ways and possibilities of their achievement, evaluating the results of activity, and the attitude of others towards them as an active component of self- realization, which is carried out directly through the activity of a future teacher. When this activity is connected with self-understanding, i.e. is meaningful, it leads to the formation of experience, which should not be considered as an activity itself, but as a conclusion from it, so self-affirmation in connection with selfunderstanding leads to the accumulation of experience. Self-affirmation also provides a communicative function, as it cannot be carried out other than in interaction with someone.

In the formation of self- realization, motivation allows to motivate the student to selfdevelopment, self-improvement. Internal factors of future teacher's self-realization are worldview, peculiarities of thinking activity and motivational sphere. Awareness of activity motives, on which the student's attitude towards professional activity depends, contributes to effective implementation in the profession. Formation of self-realization experience is connected with teaching a future teacher how to organize individual and public in university life through specific social activity, which allows effective actualization of creative abilities $[14,15]$.

Self- realization is individual and unique, and the experience formed in the process of self-realizationis the basis for self-development. The formation of self-actualization experience directly and indirectly depends on the level of human self-actualization, the level of development of individual abilities and potencies of a person, the development of his emotional sphere.

In the context of the problem, an experiment was conducted among 240 students of $3 \mathrm{rd}$ and 4th years at the Chechen State Pedagogical University to determine their readiness for self-realization. The results are shown in the following table.

Table 1. Indicators of readiness for self- realization of students of pedagogical university

\begin{tabular}{|l|l|l|l|l|}
\hline \multirow{2}{*}{$\begin{array}{l}\text { Components of self- } \\
\text { realization }\end{array}$} & \multicolumn{2}{|c|}{ CG } & \multicolumn{2}{c|}{ EG } \\
\cline { 2 - 5 } & $\begin{array}{l}\text { Entry } \\
\text { level }\end{array}$ & $\begin{array}{l}\text { Final } \\
\text { level }\end{array}$ & $\begin{array}{l}\text { Entry } \\
\text { level }\end{array}$ & $\begin{array}{l}\text { Final } \\
\text { level }\end{array}$ \\
\hline self-discovery & $30[\%]$ & $36[\%]$ & $32[\%]$ & $61[\%]$ \\
\hline self-perfection & $29[\%]$ & $34[\%]$ & $30[\%]$ & $64[\%]$ \\
\hline self-affirmation & $33[\%]$ & $38[\%]$ & $28[\%]$ & $57[\%]$ \\
\hline
\end{tabular}

According to the results, in the control group the data on self-realization, self-perfection and self-affirmation were identical at both the entry and final levels. At the end of the experiment the result doubled in the final level groups, which was facilitated by thematic classes, students' independent work and extracurricular activities.

\section{Discussion}


The process of becoming self-actualization of a future teacher in the course of professional training in higher education institution is considered not linearly, but stage-by-stage, as a transition from one stage to another with transformation of its functional characteristics. Reproductive stage of future teacher's self-realization is characterized by spontaneity, students often do not use the most favorable conditions for self-realization, and where it is observed, we find a momentary benefit (for example, resolution of difficulties in passing exams, tests or other reporting). Professional priorities of such students are blurred, they do not project their professional self-development, they are not proactive. In the process of pedagogical practice they blame their failures on students (bullies, do not want to study), their parents (do not deal with children), the administration of general educational organizations (do not help, do not create conditions), university teachers (impose unrealistic requirements). Self-esteem may be overestimated, underestimated or unstable, because students do not believe in their own strength and attribute their success solely to luck. The goal orientations in professional pedagogical activity are unconscious and are in no way related to the students' achievements. The performing stage of future teacher's selfactualization is revealed in typical situations of learning activities, when students know in advance the course of the study session, types of activities, forms of analysis and control of the results. At the same time future teachers aspire to self-analysis and analysis of their activity, life goals and plans, to design ways of self-realization in the forthcoming professional and pedagogical activity.

Educational practice shows that self-assessment varies depending on the situation. For example, when students see it as an opportunity to realise their professional intentions, then self-assessment is close to adequate. Or, when students are unwilling to work with 'difficult' students who do not share their enthusiasm for the subject, but demonstrate a particular attitude towards 'comfortable' students. Such students are not characterised by pedagogical empathy, openness in communication and interaction with students. Students are seen as objects of pedagogical influence, requirements, prohibitions. In such a situation future teachers position their authoritarian style of management and communication, active activity, which is aimed at rationing and regulation of students' activities mainly by coercion and demand.

The creative stage of self-realisation is characterised by sustained motivated selfrealisation in situations of educational and pedagogical activity. The professional priorities of such students are more related to the nature of pedagogical activity. The subject content of learning is seen as a material for interaction with students. This is due to the formation of their self-esteem: it is more adequate, depends on the prospects of success in teaching, communication with students, as well as knowledge in the subject area. Difficulties that students experience in real communication with students in the process of pedagogical practice are deeply wounding and can seriously shake their self-esteem. At the same time, these difficulties and failures are often a major impetus for them to reflect on their professional behaviour and to search for better methods and pedagogical techniques.

The subjective stage is characterised by the fact that student's self-realisation is stable in situations of learning and professional activity. At this stage, self-assertion as a component of self- realization develops more vividly. At the same time, students are active and independent in searching for self-actualization opportunities in almost any situation. Such students are open to partner, dialogical interaction with a significant "Other", are capable of empathy and empathy, thus disposing the interlocutor to themselves. Some students have organisational skills naturally developed or they are specially shaped. In any case such students fascinate others with their sincerity, goodwill, tolerance and willingness to help people.

\section{Conclusions}


Theoretical analysis of modern scientific discourse research and practical experience of professional activity allow us to summarize the following:

- the development of a future teacher's personality in modern socio-cultural space is conditioned by the motivational settings to achieve positive results of own activity, conditions of self-realization in the process of university training, competence to improve the available experience and to act as a navigator in the information field;

- the participation of students of pedagogical universities in national projects and contests of pedagogical skills;

- provision of modern infrastructure for the system of higher education teacher training;

- Professionalization of a modern teacher in the context of digitalization should be based on the country's civilizational heritage and socio-cultural context;

- Self- realization of future teachers should be based on dialogic interaction with the cultural and educational environment of higher education institution.

\section{References}

1. A.Z. Khabibullina, E.F. Nagumanova, O.V. Shemshurenko, Comparative study of Russian and Tatar literature as a factor in the research training of teachers of verses in the Republic of Tatarstan, In the collection: Development of professional competencies of teachers: main problems and values, Collection of scientific works of the $\mathrm{V}$ International Forum on Pedagogical Education, 220-225 (2019)

2. M.Y. Kirova, Psycho-pedagogical aspect of enculturation of personality of a future teacher of foreign languages, Scientific Notes of N.G. Chernyshevsky Zabaikalsky State Humanitarian-Pedagogical University 6 (47), 12-16 (2012).

3. K.Y. Breshkovskaya, M.A. Kuvyrtalova, M.I. Petukhova-Levitskaya, Modern problems of science and education 6, 349 (2016)

4. A.V. Lubkov, Education and science 22 (3) (172), 36-54 (2020).

5. A.N. Shamov, O.M. Kim, Russian and foreign pedagogy 2 (3) (73), 70-87 (2020).

6. N.A. Astashova, S.K. Bondyreva, A.P. Smantzer, Education and Science 20 (7), 32-67 (2018).

7. A.S. Akmaeva, Advances in science 1, 74-75 (2008).

8. N.M. Boritko, Cultural approach in education, Modern stage of education modernization: resources of sustainable development, Materials of Russian scientificpractical conference, in 4 parts (2016).

9. I.V. Rudenko, N.I. Fedorova, I.V. Muskhanova, S.A. Alieva, B.C.A. Kasumova, Z.I. Gadaborsheva, E.V. Gunina, K.B. Tumarov, Journal of Sustainable Development 8 (6), 45-50 (2015).

10. I.V. Muskhanova, F.V. Mezhidova, Azimuth of Scientific Research: Pedagogy and Psychology 2 (11), 57-60 (2015).

11. I.V. Muskhanova, Psychology and Psychotechnics 5 (32), 81-84 (2011).

12. I.A. Kolesnikova, Pedagogical reality in the mirror of inter-paradigmatic reflexion (SPb., 2008)

13. N.K. Sergeev, V.V. Serikov, E.P. Belozertsev, et al., Continuing Teacher Education: Theory and Practice (Volgograd State Social-Pedagogical University, Volgograd, 2016).

14. T.Y.Vorobyeva, V.A. Vorobyeva, Leading trends in the development of Russian education in the modern world, In the collection: Russia and Europe: the connection of 
culture and economy. Materials of XXIII International scientific-practical conference. Ed. by Uvarina N.V. 44-47 (2019)

15. E.A. Gatalskaya, Enigma 1, 13-1, 114-118 (2019). 